\title{
Lost in translation: the valley of death across preclinical and clinical divide - identification of problems and overcoming obstacles
}

\author{
Attila A. Seyhan ${ }^{1,2}$ (D)
}

\begin{abstract}
A rift that has opened up between basic research (bench) and clinical research and patients (bed) who need their new treatments, diagnostics and prevention, and this rift is widening and getting deeper. The crisis involving the "translation" of basic scientific findings in a laboratory setting into human applications and potential treatments or biomarkers for a disease is widely recognized both in academia and industry. Despite the attempts that have been made both in academic and industry settings to mitigate this problem, the high attrition rates of drug development and the problem with reproducibility and translatability of preclinical findings to human applications remain a fact and the return on the investment has been limited in terms of clinical impact.

Here I provide an overview of the challenges facing the drug development, and translational discordance with specific focus on a number of "culprits" in translational research including poor hypothesis, irreproducible data, ambiguous preclinical models, statistical errors, the influence of organizational structures, lack of incentives in the academic setting, governmental funding mechanisms, the clinical relevance of basic research, insufficient transparency, and lack of data sharing in research. I further provide some suggestions and new strategies that include some new aspects on open innovation models, entrepreneurship, transparency, and decision making to overcome each of the many problems during the drug discovery and development process and to more dynamically adjust for innovation challenges with broader scientific feedback.
\end{abstract}

Keywords: Translational research or medicine, Valley of death, Preclinical and clinical research, Reproducibility of research findings, Drug discovery and development

\section{Background}

Translational research also referred to as translational medicine or translational science refers to the "benchto-bedside" process that harnesses knowledge from basic scientific research into clinical research to create novel treatments and treatment options devices, medical procedures, preventions, and diagnostics essentially forming a bridge between basic research and clinical research [1-5]. For clinical researchers and other health workers, translational research refers to

Correspondence: Attila_seyhan@brown.edu; Attila_seyhan@yahoo.com ${ }^{1}$ Joint Program in Cancer Biology, Brown University and Lifespan Cancer Institute, Warren Alpert Medical School, Brown University, Providence, RI, USA ${ }^{2}$ Department of Pathology and Laboratory Medicine, Warren Alpert Medical School, Brown University, Providence, RI, USA translating research into clinical practice in the form of new treatments and knowledge that actually reach the patients or populations [5]. Despite the differences in semantics, basic science is the earliest stage of research, conducted for the advancement of knowledge, often without any concern for its practical applications whereas translational research is the process of applying these discoveries generated through basic scientific inquiry to the treatment and prevention of human disease. Thus, translational research acts as a bridge between basic and clinical research.

Despite significant investments in basic science, advances in technology and enhanced knowledge of the human disease, translation of these findings into therapeutic advances have been far slower than

(c) The Author(s). 2019 Open Access This article is distributed under the terms of the Creative Commons Attribution 4.0 International License (http://creativecommons.org/licenses/by/4.0/), which permits unrestricted use, distribution, and reproduction in any medium, provided you give appropriate credit to the original author(s) and the source, provide a link to the Creative Commons license, and indicate if changes were made. The Creative Commons Public Domain Dedication waiver (http://creativecommons.org/publicdomain/zero/1.0/) applies to the data made available in this article, unless otherwise stated. 
expected [6,7] and the return on this investment has been limited in terms of clinical impact.

There is a consensus both in academia and industry that there is a crisis involving the translatability of preclinical science to human applications and that most research findings are irreproducible or false $[8,9]$.

In a time of increased cost (it has been estimated that for every dollar spent on $R \& D$, less than a dollar of value is returned on average) [10], high-attrition rates, and length of time required for new drug development [11, 12], and constrained resources, translational research needs a renewed outlook. For example, should the funds be moved from preclinical to translational research projects more specifically linked to human disease, especially for those involving the discovery and preclinical development of new drugs? Would such a strategy in the long term improve the translatability of preclinical findings and result in better long-term patient outcomes? One way to address these outstanding questions would be to evaluate the potential culprits leading to the failure of translating preclinical findings to human studies.

In this article, I provide a fresh perspective on the challenges of translational research, present examples of potential weak links that might be contributing to the failures, and potential strategies to mitigate those problems.

\section{Why translational research / medicine matters and why it is challenging}

Of the many known human diseases (in the order of thousands), for approximately 500 have a treatment approved by the regulatory agencies. Even when a new treatment is shown to be effective, it can take several years to identify and serve all patients who could benefit. Furthermore, as discussed by Zeggini et al. [13] most common human diseases are highly complex chronic diseases and exhibit a variable disease course and response to therapy. For example, it was reported in the literature [14] that 10 of the best-selling drugs in the United States, to achieve one patient with a good response, between 4 to 25 patients must be treated. This carries a significant burden on health risks and resources by exposing those patients who are treated without achieving a clinically significant response or to the risk of harm through the development of unnecessary side effects of the drug. This emphasizes the need to develop better ways to targeted therapies which essentially requires a better and more effective translational and precision medicine strategy. Therefore, a better understanding of the genetic, epigenetic and other molecular defects leading to complex diseases can provide new insights into fundamental biology and translational opportunities.
As illustrated in Fig. 1, translational research is a discipline that enables the results of basic science applicable to clinical science as such it is defined as a research approach that seeks to move from bench to bedside. More specifically, it is a process in which the ideas, insights, and discoveries generated through basic scientific inquiry are applied to the treatment and prevention of human disease - thus playing a critical role between basic research and clinical research. It includes intermediate steps such as identification of targets, drugs, biomarkers, pathways, and development of and testing in animal models and human tissue xenograft models. Thus, it bridges the gap between the basic science that identifies novel biomolecules involved in or consequence of diseases and their incorporation into clinical application. In that context, the term translational research has been applied more generally where scientists aim to translate fundamental research discoveries into practical products and applications.

Therefore, the main objective of the translational research is to make sure that the discoveries that advance into human trials have the highest possible chance of success in terms of both safety and efficacy in human studies. Eliminating the ones likely to fail earlier in the process can significantly decrease the overall cost of developing new products. Thus, the ultimate goal of translational research is to take early discoveries from preclinical space mostly conducted in academia or industry to the point of investment.

However, there is a bias to view translational research as a linear process in which mice and rats are the bridge between basic science and human clinical studies. As discussed in the literature $[15,16]$ and illustrated in Fig. 1 , translational research is a continuous process which spans five sequential areas of activity (T0-T4) and also encompasses clinical research (T1-T3). Although the illustration of the distinct phases of translational research implies a linear model with a beginning and end, in fact the operational phases of translational research include many feedback loops with interdependent phases across the T0-T4 phases which requires continuous data gathering, analysis, dissemination, and interaction as well as the discrete translational hurdles that must be overcome (Figs. 1 and 2) $[15,16]$.

For translational research to operate more effectively, functional interactions should exist between academia, government, and the community and the financing and operational components of industry (biotech and large pharma) [17].

\section{Common challenges to translational research/medicine}

Our ability to translate discoveries into approved drugs that can help patients is a challenging process. The implementation of translating scientific discoveries into 


\begin{tabular}{|c|c|c|c|c|}
\hline $\begin{array}{l}\text { Basic science } \\
\text { research }\end{array}$ & $\begin{array}{l}\text { Translation } \\
\text { to human }\end{array}$ & $\begin{array}{l}\text { Translation to } \\
\text { patients }\end{array}$ & $\begin{array}{l}\text { Translation to } \\
\text { practice }\end{array}$ & $\begin{array}{l}\text { Translation to } \\
\text { community }\end{array}$ \\
\hline $\begin{array}{l}\text { Preclinical and animal } \\
\text { studies }\end{array}$ & $\begin{array}{l}\text { trials } \\
\text { Safety, Proof of } \\
\text { Mechanism and } \\
\text { Proof of } \\
\text { Concept, PK/PD }\end{array}$ & $\begin{array}{l}\text { trials } \\
\text { dose selection, } \\
\text { Proof of Efficacy, } \\
\text { safety }\end{array}$ & $\begin{array}{l}\text { Phase } 4 \text { clinical } \\
\text { trials and clinical } \\
\text { outcomes research }\end{array}$ & $\begin{array}{l}\text { Population-level } \\
\text { outcomes research }\end{array}$ \\
\hline $\begin{array}{l}\text { Defining pathobiology, } \\
\text { mechanisms, targets, and } \\
\text { lead molecules and initial } \\
\text { regulatory interaction }\end{array}$ & $\begin{array}{l}\text { New methods of } \\
\text { diagnosis, } \\
\text { treatment, and } \\
\text { prevention }\end{array}$ & $\begin{array}{l}\text { Controlled studies } \\
\text { leading to effective } \\
\text { care, benefittrisk } \\
\text { profile, health } \\
\text { economic data }\end{array}$ & $\begin{array}{l}\text { Delivery of } \\
\text { recommended and } \\
\text { timely care to the } \\
\text { right patient, post } \\
\text { marketing safety, } \\
\text { new indications }\end{array}$ & $\begin{array}{l}\text { True benefit to } \\
\text { society }\end{array}$ \\
\hline Translation from & $\begin{array}{l}\text { basic scienc } \\
\text { studies }\end{array}$ & to human & \multicolumn{2}{|c|}{$\begin{array}{c}\text { Translation of new data into the } \\
\text { clinic and health decision } \\
\text { making }\end{array}$} \\
\hline
\end{tabular}

Fig. 1 Operational phases and associated challenges for translational research. Translational research has many layers (T0-T4) and associated operational obstacles that must be overcome. T0, basic science research that define cellular mechanisms, their relationship to disease and, consequently, the identification of therapeutic targets and development of methods of treatment (new molecular entities). T1, is the proof of concept studies conducted in volunteer human subjects as phase 1 clinical trials that aim to define proof of safety, mechanism, and concept. T2, phase 2 and 3 clinical (ideally randomized) trials that are necessary to test the proof of efficacy of the therapeutic agent in cohorts of patients representing the relevant disease that may include control groups. T3, phase 4 clinical trials that are associated with optimizing the therapeutic use of a therapeutic agent in clinical practice. T4, Population-level outcomes research or comparative effectiveness research aims to determine the ultimate utility and cost effectiveness of a therapeutic agent relative to others currently in use. Translation from basic science to human studies form the critical path, as defined by the FDA, or the "valley of death", as defined by the pharmaceutical industry. This "valley of death" encompasses T0-T2 phases of research. However, each of these phases have overlapping sets of challenges as discussed in the text. Adapted from [15, 16]

relevant and clinically useful products and applications is not identical to the process of hardware or software development or manufacturing, although exhibiting similar principles in many of its aspects, such as the employment of a value-added chain or a map for the process. As illustrated in Fig. 1, translational medicine is an organic, reiterative process that requires continuous interactive feedback between varied disciplines to ensure its success and ability to innovate and is defined based on the operational hurdles that must be overcome. Translational medicine therefore embodies many loosely integrated distinct activities distributed across the academic, pharmaceutical or biotech industry, and governmental and other private sectors.

The traditional method of identifying genes in vitro, followed by generating experimental animal models of human disease in vivo, has been a challenging process because the targets and drugs developed in animals have often fail in human studies $[18,19]$. Despite the usefulness for better understanding of disease pathobiology and the mechanism of drug action on targets, the predictive utility of animal models studies is less than desired [3], especially in the context of studies of single knockouts in specific disease models and mouse strains [18].

Despite the significant efforts made in recent years to improve the drug development process by improving the efficacy- and safety-related issues of clinical trials; however, the results have been mixed and the failure rates of human clinical trials are still high [12, 20]. Even with the fascinating observations and creative science, most of the basic scientific discoveries fail to get into the therapeutic development process and often get lost in translation because they are irrelevant to human disease or lack funding, incentives, and technical expertise to advance any further. These potentially important discoveries cannot cross an ever-widening gap in funding and support for the type of research that moves basic science findings down the path toward therapeutic development. This so-called "the translational gap" has come to be called by many the "Valley of Death" (Figs. 1 and 2) [21, 22]. Increases in National Institutes of Health $(\mathrm{NIH})$ spending on biomedical research have not resulted in increases in new treatments and cures. Despite this, early discoveries still remain in what has been called the "valley of death," the gap between bench research and clinical application. To address this 


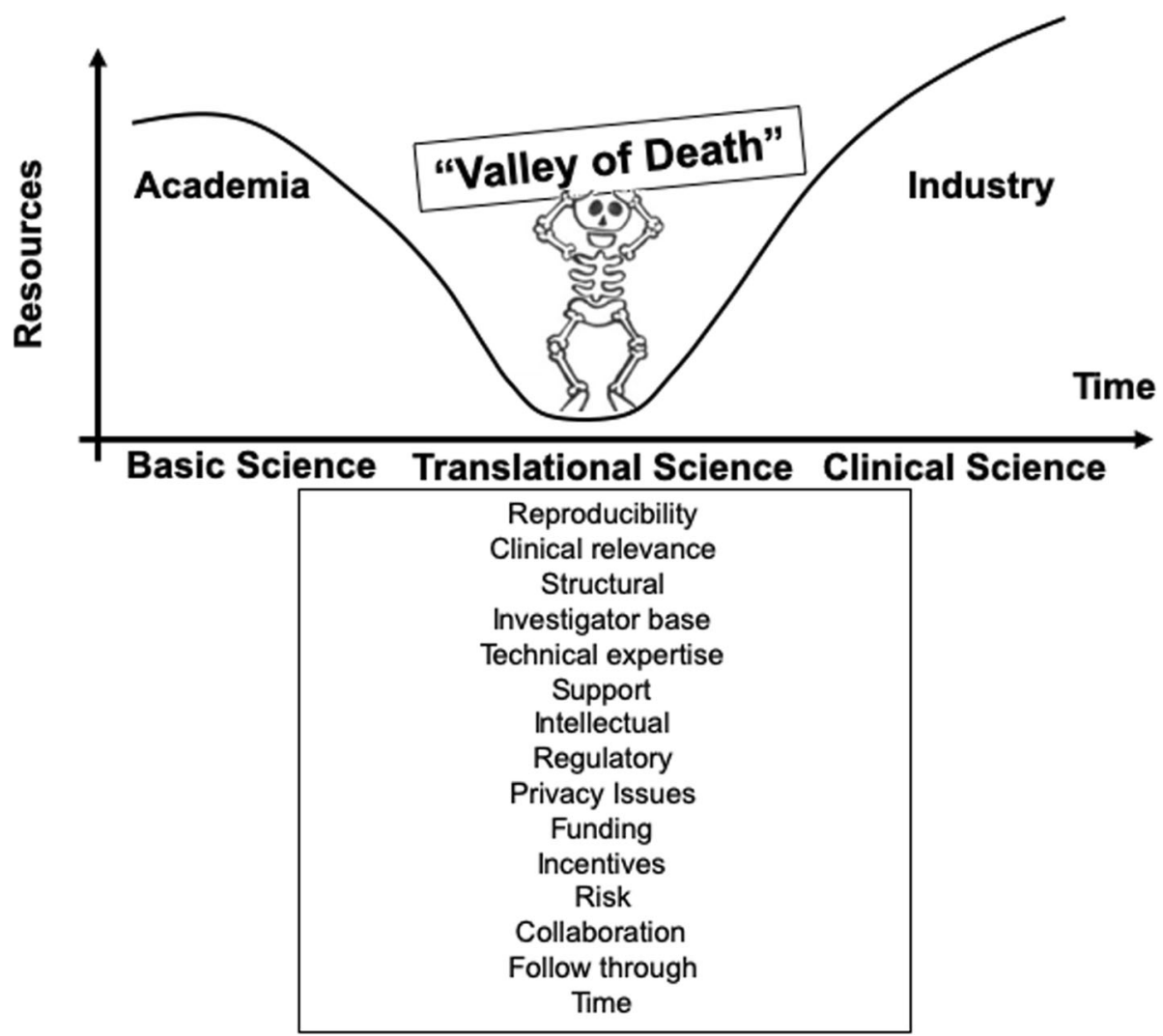

Fig. 2 Illustration of the valley of death in biomedical research. Between basic scientific research and clinical research is what's known as translational research often referred as "the Valley of Death," where promising discoveries meet their demise. To cross the "Valley of Death, several key requirements must be in place to move these discoveries into new treatments, diagnostics and preventions

issue, there has been significant discussion in the literature and scientific community about the causes of this phenomenon and how to bridge the abyss [22].

The process of getting a new drug, from first testing to final FDA approval and ultimately to market is a long (from discovery to approval of a new drug takes more than 13 years), costly, and risky and almost $95 \%$ of the drugs entering human trials fail [7, 23-28]. According to the National Institutes of Health (NIH), 80 to $90 \%$ of research projects fail before they ever get tested in humans and for every drug that gains FDA approval, more than 1000 were developed but failed. Almost $50 \%$ of all experimental drugs fail in Phase III trials. Hence, moving new drug candidates from preclinical research into human studies and the approved drug is only approximately $0.1 \%$. The majority of projects fail for problems unrelated to a therapeutic hypothesis which may be due to unexpected side effects and tolerability [29, 30]. More recent analysis suggests that, despite efforts to improve the predictability of animal testing, the failure rate has actually increased [31]. The major causes of failure are lack of effectiveness and poor safety profiles that were not predicted in preclinical and animal studies [7, 19, 23-25, 32].
Moreover, the development of a newly approved drug costs about $\$ 2.6$ billion [33, 34], a $145 \%$ increase, correcting for inflation, over the estimate made in 2003. The analysis was based on the data obtained from 10 drug companies on 106 randomly selected drugs tested in human trials between 1995 and 2007 [33, 34].

It is suggested that medical knowledge has a doubling time every 18 years, while emerging disciplines including nanotechnology, double on the average of every 2 years [35]. It is also reported that the efficiency of $R \& D$ of new drugs in the US halves every 9 years [36]. This phenomenon is sometimes referred to as Eroom's law the reverse of Moore's law for microprocessors [36]. In other words, the cost of getting a drug developed and approved will double every 9 years. If the business is conducted the usual way, the biopharmaceutical industry would have to spend $\$ 16$ billion on single drug development in the year 2043. This would force the industry to develop only the most profitable drugs -- not the ones most needed (http://ecorner.stanford.edu/videos/4224/ Moores-Law-for-Pharma). Basically, from the late '80s through the late ' $90 \mathrm{~s}$, the cost of drug $R \& D$ spending tended to level out. However, that is where the first wave 
of biotech drugs started coming through the market. Biotech drugs like antibody-based drugs commonly referred as to "biologics" are different in that it's a completely different mode of action, it's a completely different platform from traditional small-molecule pharmaceuticals and they are costly.

\section{The valley of death - where most preclinical findings find their demise}

The major obstacle in translating discoveries from basic research to human studies and getting them approved by the FDA is well known and this is often referred to as the "Valley of Death' (Figs. 1 and 2). In biomedical research, the main objective of translational research is to have an indepth understanding of health and disease state of the organism that is studied and the underlying molecular factors contributing to disease and mechanism(s) associated with it with the goal of 'carrying across' this knowledge to treat disease and condition. Translating a basic discovery into a potential drug candidate or biomarker that is ready to be tested in humans is a complicated, time-consuming process that requires collaboration between the academic scientists who make discoveries and clinicians. Translational research thus aims to apply fundamental knowledge gained from basic research activities to the human condition. However, translational research is more challenging and costlier to conduct than basic research because it often involves complex organisms (i.e., animal models, humans). As ideas are moving forward in the process, they become relatively less risky, but the research becomes exponentially more expensive, especially in later-stage trials in humans. To be translational in biomedical research, information is often gathered from the wide range of molecular and cellular biology research, primarily using in vitro cell culture, patient primary cell, and in vivo animal models which is then applied to restore healthy state [18].

Of course, the quality of research findings (i.e. a change in pathophysiological changes leading to disease incidence and/or the development of therapy) is predominantly contingent on the quality of the input data and the methods for their processing and interpretation. The acquisition of information that may be less relevant than anticipated further corrupts the process as well as the use models including animal models that are irrelevant to human disease.

Of course, improving the quality of hypotheses before testing them will save a lot of time, resources, and grievances, and potentially warrant success. This, of course, requires careful thinking, searching the literature and conducting a proper assessment of the likelihood of success before committing to testing a hypothesis.

As discussed recently [21], there is an increasing consensus that the significant resources are being allocated into biomedical research, and significant gains made in understanding disease mechanisms, are not resulting in proportional gains in new treatments, diagnostics, and prevention. Over the past several decades, basic and clinical research are no longer on the same track and have diverged. The biopharmaceutical industry, which in the past was expected to carry discoveries across the divide, is now more interested in focusing on clinical research on candidate drugs that are more likely to succeed the regulatory approvals, and marketing. The vacuum left behind is often referred to as the 'Valley of Death' - and neither basic scientists, preoccupied with discoveries nor clinical scientists and clinicians, busy with clinical studies, are keen to communicate or cooperate. This has decreased the interaction between basic and clinical scientists diminishing the transfer of information between these entities. At the same various omics platforms are generating data that could lead to potential novel drug targets and other discoveries that both the preclinical and clinical scientists both are having trouble parsing through. Despite biopharma is spending more on research, it is disproportionately delivering fewer products, and is no longer able to take forward most basic science discoveries.

Furthermore, most research findings cannot be replicated and many of the findings even after replicating have no immediate utility or impact (however, they may lead to new avenues result in a huge benefit in the future).

The promotions in basic scientific research have been judged by number of funded grants based largely on the scientific publications in top journals, not on how much they have advanced the clinical science and medicine. Conversely, many clinicians whose success measured by how many patients they treat often have little time or motivation to do research and seek funding opportunities to do it which is increasingly becoming more competitive and difficult.

Crossing the 'valley of death' is not only about science. In addition to the scientific, design, and other reasons, this gap arises because of a systematic funding gap and also because of a knowledge and reward gap. The ability of research teams involved in the drug development process, as well as project management and negotiation skills, the track record of the organization, Intellectual property, market opportunity and a demonstrable competitive advantage all impact upon the ability to move the drug candidates towards FDA approval and marketed drug status.

\section{The usual suspects}

Evidence suggests that many published research findings in biomedical research are misleading, not as robust as they claim, or cannot be reproduced [8]. Because of this, the problem with the reproducibility of findings 
preclinical findings and their translatability to human studies is now widely recognized by both the biopharmaceutical industry and academic researchers.

The scale of the problem could be as plain as the simple differences in methodological differences (for example, type of coating on tubes, what temperature are cells grown, how cells are stirred in culture, or subtle differences in medium such as $\mathrm{pH}$ or ingredients on which they are cultured) can result in complete failure to replicate the results.

As discussed in the literature [24], there are many other reasons why drugs fail the development process including an increased focus on chronic and degenerative diseases and tests that use comparative drug effectiveness. It may be that the effect seen in cultured cells did not translate into an effect in animal studies [19], or the candidate drugs did not have good safety profiles in animals for unexpected reasons or if they had poor PK/ bioavailability and PD profile or they fail due to poor or lack of efficacy and safety issues in human clinical trials $[12,24,25,29,37,38]$ or they were no more effective than the current drugs or drugs do not work on their intended targets.

There are many reasons why translational research might fail. These could be as simple as insufficient understanding of the nature of the translational process, failure to effective integration of the data coming from different technological approaches to disease, the use of models, access to tissues and appropriate materials, and the need for support in increasingly complex areas such as ethics, bioinformatics and biostatistics and personal privacy in relation to carrying out research in humans [18]. These greatly hinder progress in translational science.

Furthermore, failure in translational research may be explained in part by methodological flaws and poor experimental designs in preclinical in vitro and in vivo animal studies, leading to systematic bias and thus leading to irreproducible and unreliable data and inaccurate conclusions.

A variety of other reasons may include the lack of relevance of the target or mechanism to the disease and hence leading to lack of safety and high heterogeneity of patient population where the target exists only in a subset of patients as such, the drug is effective only for a subset of patients but not for everyone.

For example, a recent report has evaluated 10 cancer drugs currently in clinical trials and found that they do not work on their intended targets [39]. The 10 smallmolecule drug candidates are designed to target CASP3, HDAC6, MAPK14, PAK4, PBK and PIM1, the HDAC6 inhibitors citarinostat and ricolinostatas well as the p38 MAPK inhibitor ralimetinib and PAK4 inhibitor PF03758309, for which a phase 1 in advanced solid tumors was terminated early due to "undesirable PK characters and the lack of an observed dose-response relationship. All 10 drugs the researchers examined have been used in at least 29 different clinical trials involving more than 1000 patients. Five of the six targets that these drugs are targeting are key for cancer cell's survival with the exception is CASP3, which is considered to induce cell death when activated.

In that case, strategies such as better use of biomarkers $[3,40-46]$ and a better understanding of the link between genome-wide sequence and association with wellcharacterized phenotypes to aid diagnosis, inform disease progression trajectories, and allow better targeting of treatments to those patients most likely to respond [13]. As described in the literature [3, 40-45], a biomarker is an objective measurement of a biological signature in tissue or blood or other bodily fluids that substitutes for and ideally predicts a clinically relevant endpoint or intermediate outcome. Biomarkers are used in disease screening, diagnosis, and monitoring; as prognostic indicators; for developing individualized therapeutic interventions; for predicting and treating adverse drug reactions, and for pharmacodynamic and dose-response studies. A valuable biomarker links the pathophysiological state and the relevant clinical endpoint. Scientific and technological advances made in recent years have enabled multiscale, longitudinal measurements (snapshots) of human biology using various biomolecules such as RNAs (mRNA, microRNAs, long non-coding RNAs), DNAs, proteins, metabolites, [32, 40-42, 47-59] derived from patient specimens from liquid biopsy or tissue biopsy or single-cell analyses to whole-body monitoring $[44,60]$ and that these advances have led to an increasing number of biomarkers for which targeted drugs are being discovered. Collectively, the integration of a variety of molecular profiling of patient specimens with deep, longitudinal profiling of the physiological state of an individual (i.e. deep phenotyping') [32, 60-63] allows us is essential to understanding the prevention, initiation, progression, and response to treatment of diseases. For example, biomarkers identified from these efforts that signal correct dosing and whether the specific molecular target has been hit in early proof-ofconcept clinical trials have led to therapeutically improved therapeutic choices, all of which have garnered US Food and Drug Administration (FDA), Centers for Medicare \& Medicaid Services (CMS), and insurance company attention. Notably, Foundation Medicine's FoundationOne $\mathrm{CDx}$ assay was recently approved by the FDA and concurrently accepted by the CMS [44].

Drugs that target novel targets and mechanisms appear to have higher attrition rates, [24, 64] but a combination of better-validated preclinical targets that have significant preclinical efficacy and safety profiles, and proof of principle data, can reduce such attrition risks. 
Additional factors may include the model systems that have been used in scientific research where human studies cannot be conducted. For example, basic scientific research using animal models has been considered to be necessary for developing new therapies for human diseases, as well as in elucidating underlying molecular and pathophysiological mechanisms that lead to or associated with the disease. Almost $90 \%$ of the animal studies the industry conducts are legally required or justified by scientific reasons [19]. The value of preclinical research mainly conducted in animal model experiments for predicting the effectiveness of therapies and treatment strategies in human trials has remained contentious. In addition, poor translation of animal studies to human studies has led to significant amounts of wasted resources [31]. It has been claimed that just only $6 \%$ of animal studies are translatable to human response [65].

Furthermore, improper use of statistical analysis methods and the misinterpretation or misuse of $p$-values appear to have a significant effect leading to inaccurate conclusions leading adding to the reproducibility crisis.

As for why clinical trials fail, this has been discussed eloquently by David Grainger (www.forbes.com/sites/ davidgrainger/2015/01/29/why-too-many-clinical-trialsfail-and-a-simple-solution-that-could-increase-returnson-pharma-rd/\#607c0b8edb8b) and others $[24,66]$ who also point to a major but simple cause for unexpected late-stage clinical trial failure i.e. the fundamental misunderstanding of the p-value. To tackle many of these problems, Colqhoun [66] proposes simple steps that could materially increase the success rate of late-stage trials. However, ascribing single reasons for candidate drug failure could be an oversimplification because there may be multiple factors contributing to the failure of the drug candidate.

Additional roadblocks affecting successful translation of early discoveries into successful clinical research may include an incomplete understanding of the science of translation, improper clinical trial designs, and low participation in studies further contributes to this problem. Furthermore, lack of insufficient institutional and organizational support for translational science.

\section{Suggestions to improve translational research}

The first step towards a solution to a problem begins with the recognition of the problem. Perhaps, to improve translational research, it may be even more prudent to improve first the quality of hypotheses before testing them. This will save a lot of time, resources, and potentially increase the chances of success. This, of course, requires meticulous thinking, planning, searching the literature, and conducting a proper assessment of the likelihood of success before committing to testing a hypothesis. As a result, more comprehensive integration of evidence coming from various in vitro, in vivo and human studies might allow the refinement of objectives and target relevance and might improve the translatability of preclinical findings to humans thus increasing the likelihood of successful drug development.

Another emerging strategy to improve translational research is the identification of candidate drugs by screening the compound libraries in less complex biological systems instead of cell lines or primary human cells that have been the workhorse of the pharmaceutical industry. There is currently interest in the use of three dimensional (3D) organoids for rapid drug screening $[67,68]$ and model organisms such as Caenorhabditis elegans and zebrafish in high-throughput screens for new drugs $[18,19,69,70]$. It is becoming increasingly evident that these systems can be used to identify therapeutic targets [71] and enable understanding the biology of pathways and gene products, and the ability of a compound or library of compounds to exert their functional effects in complex biological processes is directly assessed.

Another emerging compound library screening strategy is the use of so-called clinical trials in a dish (CTiD) - which bridges preclinical testing and clinical trials. CTiD allows testing potential therapies for safety or efficacy on cells collected from a representative sample of human patients enabling the development of drugs for specific populations leading to the selection of safer drugs to move into clinical development [72], resulting in a reduction in attrition and can be executed at a fraction of the cost outside of the rigid and heavily regulated clinical testing environment.

\section{Better ("deep") phenotyping of patients}

Better ("deep") phenotyping of patients is another strategy. In this approach, deep phenotyping uses various molecular profiling imaging, and clinical data collected longitudinally to define the human disease [3, 18]. Obviously, this strategy requires access to patient specimens and must overcome ethical anxieties. The so-called deep phenotyping [13, 32, 60-63] involves linking retrospective and prospective longitudinal molecular profiling and other relevant data including tissue histopathology to electronic health records (EHRs). This can lead to better clinical characterization of the study population and enable discovery of new genetic, epigenetic, proteomic or other molecular profiling associations with disease, disease subtypes. There are already several large-scale biobanks and population-based cohorts including the UK Biobank (500,000 participants), the All of Us initiative (1000,000+ participants), and the Million Veterans Program, now include linkage to EHRs [73]. Deep phenotyping by way of using EHR-linked biobank data has been used as a resource for the discovery of novel drug targets [74-77]. For example, Dewey et al. [78] used the 
exome sequencing data linked to the EHR from 58,000 patients collected at the Geisinger Health System and found that loss-of-function mutations in ANGPTL3 were correlated with the development of coronary artery disease. As a next step, Dewey et al. [78] developed a monoclonal antibody antagonist to target this protein as a potential therapeutic for disease prevention. Similarly, Graham et al. [79] have also shown that antisense oligonucleotides targeting ANGPTL3 are also protective against cardiovascular disease in humans. EHR-linked biobanks have also shown their utility in the field of pharmacogenomics to discover and investigate specific genetic variants that modulate or mediate drug efficacy, drug response or tolerance, such as those that affect metabolism [80]. For example, the electronic Medical Records and Genomics (eMERGE) Network, collaborating with the Pharmacogenomics Research Network (eMERGEPGx) reported that $96.2 \%$ of 5000 clinical subjects had at least one actionable variant for 82 pharmacogenes [81]. As of 2018 with more than 10 million genotyped customers, the consumer genomics industry is becoming a mainstream phenomenon [82]. Recently, the Food and Drug Administration (FDA) announced its approval of the first direct-to-consumer pharmacogenomics test to be performed and marketed by 23 andMe paving the way for direct-to-consumer genetic health risk tests of limited clinical utility [83]. However, concerns remain with respect to direct-to-consumer pharmacogenomic testing. For example, the 23andMe test includes eight gene panel (with a total of 33 variants that are expressed at a higher allelic frequency in the Caucasian population) involved in drug metabolism. However, variants of these genes that are expressed at higher frequency in patients of African, Asian and Hispanic populations are not included in the 23andMe test. This potentially will result in falsepositive results. For example, a recent report indicated that $40 \%$ of variants in a variety of genes reported in direct-to-consumer raw data were false positives [84] highlighting the importance of clinical confirmation testing for appropriate patient care. In addition, the genetic testing companies such as 23andMe have established a two-sided market between the consumer and the research laboratories, concerning the creation of DNA databases and biobank for scientific and financial gain which has some profound ethical ramifications [85].

\section{Drug repurposing}

Drug repurposing is another strategy to accelerate drug development and skip the early phases of roadblocks $[7,36]$. Drug repurposing evaluates drugs that are already approved to treat one indication or condition to see if they are safe and effective for treating other indications [36, 86-97]. To achieve this, a variety of computational and experimental and clinical data can be employed synergistically to analyze various types of large-scale data for drug repurposing [98]. The data set and approaches can include genetic association (genes that associate with a disease), pathway mapping (network analysis using genetic, proteomic, transcriptomic or disease data), retrospective clinical analysis (systematic analysis of EHRs, clinical trial data and post-marketing surveillance data), novel data sources (large-scale in vitro drug screens with paired genomic data, EHR-linked large biobank and patient data), phenotypic screening (high-throughput phenotypic screening of compounds using in vitro or in vivo disease models), binding assays to identify relevant target interaction (mass spectrometry, affinity chromatography), signature matching (comparing the transcriptomic or adverse effect signatures of a drug with that of another drug or disease phenotype), molecular docking (structure-based computational strategy to predict binding site complementarity between a ligand and a therapeutic target) [98]. Repurposing existing drugs for different indications or targets, drugs can be developed in 4-5 years without much risk of failure, by virtue of reverse engineering and licensing Intellectual property (IP) rights. This is because, many repurposed drugs have already passed the early phases of development, clinical safety, and bioavailability testing, thus can potentially gain FDA approvals in less than half the time and at one-quarter of the cost. However, side effects that would be acceptable for a life-threatening disease might not be acceptable for chronic disease. It is argued that repositioning a drug reduces the cost of drug development because safety tests are not needed. The argument is that, the safety data already exist for the drug because the drug works only if the dose and mode of administration remain similar. If the new indication necessitates a significantly higher dose, the drug will have to go through phase I trials again.

For example, GWAS studies have been successfully used to identify drug-repurposing opportunities, i.e., targets for which there are already approved drugs for other indications [98]. Repurposing of existing de-risked compounds to treat both common and rare diseases is increasingly becoming an attractive strategy to reduce overall development time and costs. Despite the successful identification of repurposable drug candidates using various data-driven and experimental approaches [98]; however, there are also challenges including technical and regulatory challenges that must be addressed [98].

\section{More transparency}

Another area of improvement is more transparency in scientific research. Even if all other issues are addressed, some studies sometimes are useless and or may be very difficult or impossible to replicate and even those that get into the clinical space many of those clinical studies are terminated because of futility. As discussed by Ioannidis [8], to be useful, "clinical research should be true" 
[99] and there has to be clinical impact or utility. Impact decreases when research is not transparent, when study data, protocols, and other processes are not accessible for verification or further use by others. Therefore, there has to be trust (i.e. more transparency) in scientific research. To earn that trust, there has to be a paradigm shift for a more open, transparent science where the primary goal is to test and not support hypotheses. To accomplish this, we must make some changes in several research practices that can contribute to greater transparency and reproducibility for biomedical research investigations including the availability of detailed methods and protocols and results (even the raw data), software and codes in ways that are accessible and for those who may want to reanalyze or replicate their findings.

\section{A more flexible and modular approach that engages both academia and industry}

Due to the increasing cost of drug development and high risk of attrition of successful translation of findings to human studies and funding challenges in the public research sector, a collaborative partnership model has been explored between industry and public research organizations to pool resources and reduce duplication of efforts. These efforts may include sharing broad as well as deep scientific knowledge, adopting a cross-institution development and business models, more transparency, more phenotype-specific therapies, and roader, balanced ethics discussions.

With some strategic federal and philanthropic investments, the paradigm is beginning to shift. For example, $\mathrm{NIH}$ has made some progress toward promoting translational research with some helpful trans-NIH initiatives. Examples include, National Chemical Genomics Center, Therapeutics for Rare and Neglected Diseases (TRND), Rapid Access to Interventional Development (RAID), Clinical and Translational Science Awards (CTSAS), NIH-FDA joint leadership council, clinical center, and Cures Acceleration Network (CAN) at NIH and nonprofit collaborators, and philanthropic investments (e.g. Michael J. Fox Foundation for Parkinson's Research, the Cystic Fibrosis Foundation) are aiming to move promising science through the Valley of Death.

There are many examples of active integrated drug discovery organizations such as Lead Discovery Centre, the Max Planck Institute, Germany; the Centre for Drug Research and Development (CDRD), Canada; the Centre for Drug Design and Discovery, Katholieke Universiteit Leuven, Belgium; and MRC Technology, the Medical Research Council, UK.

The pharmaceutical industry has been changing its strategies to remain competitive in the face of changing business environments and foreign competitions emerging primarily from countries such as China, India, Korea, and Brazil potentially with their R\&D and business models [100]. Many of these emerging countries are considered as the 'Future Innovators' (i.e. capital-abundant with an evolving R\&D ecosystem). These countries have built a strong base for innovation through support of academic $R \& D$ and resulting in high-impact publications, growing start-up activities, the existence of modern infrastructure and availability of a diverse talent pool, coupled with robust although mostly public but also growing private funding [101].

In addition, changing attitudes especially in academia with respect to entrepreneurial attitudes is important during biomedical innovation and new product development (e.g., drugs, biomarkers, etc.). Supporting environment, positive attitudes and orientation towards entrepreneurship are benefiting not only the inventor but also the institute hence resulting in a win-win model with potentially high-value research products. Safeguarding IP, and licensing terms of IP rights and patents is critical for the success of the open innovation model.

However, in many places, entrepreneurial traits are still being looked at with suspicion and are judged to be less important. Of course, entrepreneurial attitude is currently out of the domain in the industry except for a few pharmaceutical companies which still have some type of semi-autonomous research groups that are responsible for their research programs geared towards specific product development. The parent company often gets involved in those products market introduction (NDA) and the treatment of the target population.

\section{More advocacy and incentivization}

Translational research or medicine embodies a broad range of scientific, regulatory, and clinical disciplines. Although there are now numerous organizations currently in existence to embrace the field in its globality, there remains many other practical aspects often related to advocacy, education, incentivization, regulation, business and economic issues remain as challenges, with no focused outlet through which to address emerging issues [102]. An organization embracing the complexities of translational medicine should be considered with the goal of contributing information to all arenas of the need for translational efforts [102]. As discussed in the literature [17], the incentives must be aligned to engage basic and clinical faculty to pursue translational and clinical research. Accomplishing this goal requires structural and educational initiatives such as branding and supporting this initiative, expansion of infrastructure in informatics and appropriate research facilities including biobanking, computational biology, specific core facilities, biostatistics and others. Such a shift in the paradigm of basic and clinical research would align strategy 
with the capabilities that are unique to each organizations such as academic medical centers and could provide them with tools to realizing their potential.

\section{Teamwork and inter-organizational collaboration}

The problem of non-translatable research is not the fault of a specific group (e.g., basic or clinical researchers) but involves multiple groups. Translational research is a complex and requires a diverse skill set. Many organizations have invested in educational programs, facilities, and most advanced resources to encourage translational research. However, emphasis on creating a sustainable multidisciplinary research teams and systems seem to be the challenge. As discussed in the literature [103], teams amplify innovation during the transition phase because more and often better ideas are generated by team input than by individuals. Involvement of team in go, no-go decision making optimizes breakthroughs and limits failures as compared with an individual's evaluation.

During the selection phase of innovation, a diverse team will eliminate poor ideas more efficiently [4]. In addition, a diverse team embodies extended networks, associated with each member, which facilitates more efficient selection and retention and sustaining innovation. Teams consisting of individuals with identical backgrounds are more likely to develop a similar mind-set that leads to sequential thinking [104]. Sequential thinking results in an unimaginative method of problemsolving, using techniques common to a single discipline or field leading to innovations that are of incremental benefit [104]. On the other hand, diverse teams are associated with a higher likelihood of connective thinking, during which members dynamically make connections between very different ideas, disciplines and techniques and methods. It is argued that diverse teams that engage connective thinking are more likely to develop radical innovations [104].

The successful multidisciplinary teams emerge from shared learning and experiences which leads to team intimacy and trust [105].

The success of the translation from basic science to clinical science and eventually to the patient requires extensive collaboration between basic scientists involved in discovery research, assay developers and statisticians, and clinical scientists and clinicians who conduct the human studies, it also involves better communication and collaboration between other organizations including funding agencies, the industry and regulatory agencies (e.g. FDA, CLIA) and other stakeholders including journals., and patients and related advocacy groups. For example, journals can be very influential in setting the standards of acceptable research and whether they are innovative or impactful. Besides the impact factor, some journals now have the Altmetric Attention Score for a research output on their portals for each article they have published. The Altmetric Attention Score provides an indicator of the amount of attention that the article has received.

Because a unique role that industry plays in bringing the FDA-approved products of basic science research through product development and into clinical use, the development and initial validation of drugs or biomarkers, the final steps of obtaining FDA or CLIA approval; therefore, it is vital for basic and academic scientists to interact with their industrial counterparts and clinical scientists and at an early stage of development. It will be the industry that conducts the necessary assays on patient biospecimens or develops and markets CLIA-approved in vitro diagnostic. And of course, there must be resources and funds available to conduct such translational research which could be funded by a variety of funding agencies and industry. Therefore, a key strategic aim for successful translational research should be the formation of strong collaborations among academia, clinical medicine, and industry.

Clinical relevance is another area that deserves some discussion [8]. Ideally, findings from biomedical research should be clinically useful regardless of their eventual results. Even there is a value of "negative" results and this is rarely discussed when clinical studies are completed.

There is a higher impact in generating useful information for solving problems with higher disease burdens. However, solving problems with low prevalence or studying rare conditions with but serious consequences for affected individuals is tremendously impactful for those individuals and even others such as infectious diseases (e.g., HIV, Ebola, and HCV). Some of the findings from low prevalence or rare disease research may generate knowledge that may also be relevant to common conditions.

\section{More effective funding mechanism}

As for the funding mechanism, the reallocation of funds could help improve all research (basic, preclinical, and clinical). As discussed by Ioannidis [8] there has to be some new business model for funding mechanisms. He suggests that while discovery-based long-term research with high uncertainty and very high failure rate could be funded by NIH, DOD and other public funding agencies, applied preclinical research where uncertainty is high, but goals are clearly set with high failure rate but with some probability of success should be funded by industry who will profit if research delivers something that is impactful and useful and that the current public funding mechanism in this area should shift to clinical research. It is argued that in clinical research although the uncertainty is high it is often manageable because goals are stated clearly and results are often useful regardless of 
whether they are "positive" or "negative". Industry and Public funds (e.g., NIH, Patient-Centered Outcomes Research Institute); may fund this type of research while regulatory agencies and universities/research institutions should safeguard the independence of research.

Today's biomedical research funding mechanism often supports only small studies with short duration because they can be completed in a short time and results can be published rapidly. However, the results from these studies often require validation in separate studies with larger cohorts of patients and sometimes require long-term studies. These studies are often cannot be performed because funds required to conduct these studies exceed the resources available to the researchers. One approach to overcome this problem may be by designing more streamlined randomized trials [106, 107] however, even for such trials, the cost may still be an issue. One approach to address this issue may be the participation of the pharmaceutical industry by contributing more funds towards these trials.

The rationale is that there must be some type of financial gain from biomedical research, especially in an era of limited resources [8]. This is often done with formal modeling (value of information) [108]. However, different studies may require very different levels of financial investment and their potential financial yield may be highly variable. For example, clinical trials are very costly. In most cases, the benefits of impactful biomedical research often offset the cost of investment $[109,110]$. It has been suggested that streamlining research could help make research better by reducing the eliminating trials that are underpowered, lacks precision, duration, and proper outcomes that can be impactful and useful. Impactful or useful research is patient-centered (i.e. biomedical research findings benefit patients or preserve health and enhance wellness) and should not be centered on the needs of researchers or clinicians or sponsors.

\section{More effective decision-making process}

Complexity in drug discovery and development process is quite high and the level of uncertainty is significant. The available data is limited (representing all aspects of disease and treatment), while time and resources are always a limiting factor to explore a wider space. Uncertainties and risks are prominent in every stage of the drug development process because drug discovery and development is a complex logistic process that requires multiple and continual expert feedback on go/no-go decisions (Fig. 3) from a wide range of specialists in various areas of research [112]. During this process, new molecular entities emerge with activity against specific and promising molecular targets of importance for a specific disease. These candidate New Chemical Entities (NCEs) are then evaluated for their efficacy, specificity, safety, toxicity, pharmacokinetics (PK), pharmacodynamics (PD), and metabolism before they can be considered safe to test in human [112]. Human trials include a rigorous series of testing in human volunteers and patients through phases one to three before the New Drug Application (NDA) for marketing approval can be made. During this aforementioned discovery and development processes, a series of go/no-go decisions must be made at specific process points to decide whether or not to proceed the discovery (from target selection to the Investigational New Drug (IND) application and development (from IND to New Drug Application (NDA) processes [113]. These go/no-go decisions are often dependent on decisions by a group of specialists with varying expertise in a specific field [113]. The common approach is that specialists or experts involved in the formal decision-making process of a particular project use intuitive decision-making rather than structured approaches [112, 114, 115]. The knowledge as compared with the known unknowns and unknown-unknowns is a real challenge for making binary go/no-go decisions on $R \& D$ project continuation. This uncertainty is even further magnified with all aspects of disease pathophysiology, patient heterogeneity, treatment options and each of treatment effects which all impact the decisionmaking process. Therefore, project management based on risk assessment is science itself [116]. Accordingly, recently a few interesting simulation experiments have been conducted to evaluate the level of error in decision-making process $[112,115]$. These studies suggest that specialists involved in the R\&D decisionmaking process vary significantly in their intuitive judgments of benefit and risk in go/no-go decisions during the R\&D process. The lack of concordance and variability concerning go/no-go R\&D decision-making cases selected in these studies may represent decisions made in the real world. Such decisions are usually made based on incomplete information, and personal bias and variability of disease area expertise and background between experts in the field.

It has been suggested by others that [115], by modeling decision-making in real cases from initial drug discovery to late development and marketing. In pharmaceutical industry $R \& D$, rational decision-making can be managed by a group of 10-15 experts [59] when mean group judgments over a series of decision points are clear go decisions. However, the number of people needed for a decision with a chance to succeed was 100 for early R\&D projects increasing with RD project complexity [112]. When mean group judgments from one decision point to another vary from go to no-go, there will be a need to expand R\&D expert input. In such cases, the drug development processes take on the form of an open innovation model. 


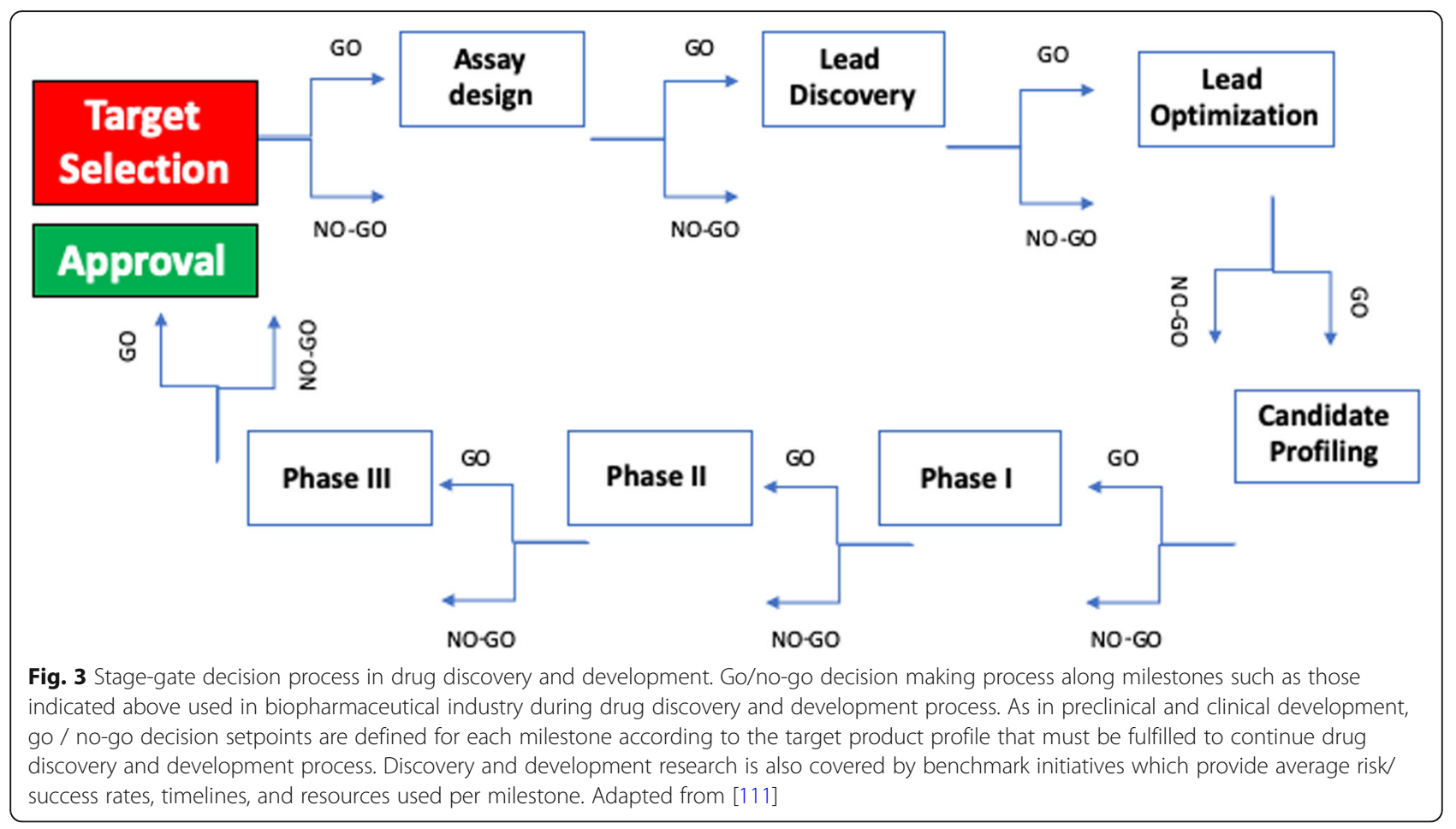

Ringel et al. [117] found that most obvious factors like company size and R\&D spending did not correlate with New Molecular Entity (NME). Interestingly, the study found that the level of science in a company as measured by the number of peer-reviewed literature and the presence of experienced decision-makers with a successful track record significantly correlated with a positive outcome. Butler argued that [21] the division of $R \& D$ is one of the factors contributing to clinical failures because of inadequate handovers.

\section{Artificial intelligence (Al) and machine learning to improve decision-making}

As discussed previously in the literature [32] and others, the future will also be affected by using artificial intelligence (AI) and machine learning to help decision making. Machine learning algorithms can identify features, and then use those features to make predictions or classify new data faster, more systematically, and sometimes better than any human to answer questions and to get insight into how to analyze the ever-growing amount of large datasets. AI can handle the complexity of the rules that must be applied to understand these large data.

Several new generation companies are taking advantage of this revolution. For example, Cloud Pharmaceuticals, a company focusing on AI-based drug discovery is using this technology to find new drug targets, new mechanisms, and novel first-in-class drugs. For example, the US federal government's Tox21 program, a collaboration among the
Environmental Protection Agency, the National Institutes of Health, and the Food and Drug Administration, maintains a large data set of molecules and their toxicity against key human proteins which is an opportunity to apply this large data to AI in search of features of association between structure, properties, function, and possible toxic effects.

In addition to identifying potential toxicities, machine learning algorithms could predict how a candidate compound might respond to different physical and chemical environments. This can help scientists understand how that compound or molecule might behave in various tissues in the human body.

AI could also suggest the structure of a new therapeutic molecule from scratch. For example, companies including Exscientia, an AI-driven drug discovery company, are using machine learning for drug discovery by mimicking the decision making of a medicinal chemist while also learning from the inputs of real human medicinal chemists. These developments suggest that in the near future, the drug targets and the molecules designed to bind them will all be influenced by the outputs of their AI platform.

In addition to the potential of AI in drug discovery, many scientists are also excited about the possibilities that AI offers, especially when it can be used to find new therapies or identify patients who are more likely to respond to specific therapies for difficult-to-treat diseases.

Furthermore, the AI revolution is already providing new tools to physicians in decision making. Several recent publications $[118,119]$ highlight the potential utility 
of AI in cancer diagnostics and cancer immunotherapy [120]. The recent big data revolution accompanied by the accumulation of comprehensive molecular (e.g. (genetic, genomic, proteomic, epigenomic and others) and clinical data set will enable the application of AI to this large data set to help decision making including disease diagnosis. The emergence of $\mathrm{AI}$ and machine learning have been recognized by academic and industry researchers, and regulatory agencies alike as the next natural step to analyze large data set and help in decision making. For example, in a recent report [118] researchers re-trained an off-the-shelf Google deep learning algorithm to identify the most common types of lung cancers and found that the AI performed almost as good as experienced pathologists when it was used to discriminate between adenocarcinoma, squamous cell carcinoma, and normal lung tissue [118]. Similarly, in another study researchers used machine learning and retrospectively identified key features associated with a specific response to anti-PD-L1 therapy that underscores cancer immunotherapy success. They then applied 36 different features-multi-modal data set into their machine learning algorithm and identified 20 features that could predict increases in potential tumor-fighting immune cells in a patient's blood after treatment. When they analyzed these features as a panel, they were able to describe $79 \%$ of the variation in patient immune responses which potentially allows better target immunotherapy treatment to those who will benefit [120].

However, there are also limitations of AI. AI is also limited by the quality of the data. If the data is erroneous, then the results are likely to be inaccurate. There is still need for human to put it all together. AI and machine learning will only help the process of drug discovery and development faster, more efficient, and better.

\section{Reconsider the business model}

We must also find ways to change the business model of biomedical research by reconsidering incentives such that basic and clinical researchers in academia are interested in translational research and can be rewarded for it.

It is argued that "big science" projects that have grandiose ideas and goals often fail or take many years to deliver. As discussed earlier [121], a likely contributor to this problem is that biomedical research is a highly fragmented industry that is organized in silos. Biomedical organizations have generally grown organically beginning from earlier discoveries, often serendipitously, which typically is organized horizontally along with functional "silos," areas of expertise where the depth of knowledge in one particular area is critical. Despite its effectiveness for fostering excellent solutions for primary scientific questions, such horizontal silos often generate barriers if information must be shared between silos. In contrast, in a vertical structure such as in manufacturing industries, formal hand-off processes are designed such that discoveries are rapidly and efficiently conveyed to others who require the information for the construction of the end product. This enables rapid vetting of ideas, eliminating poor concepts, and fostering the acceptance of better concepts. Of course, this is an oversimplification of two different industries one is much simpler while the other being highly complex and involves human life.

In a vertical approach, there are a several experts within a single organization with a focus on coordination of multiple disciplines, using shared resources and emphasizing hand-offs between entities. This enables rapid advancement towards a useful product. Contrastingly, in a horizontal approach, early discoveries are not advanced towards a useful product possibly due to duplication of efforts across disciplines.

National Cancer Institute's (NCI) Early Detection Research Network (EDRN) discussed these issues relating to each of the major constituent groups and recommended several solutions to improve the translational research process [121]. It is stated that EDRN promotes a vertical approach for conducting in this case "biomarker research", whereby biomarkers are developed, refined and analytically and clinically validated all within one organization with a focus on coordinating multiple resources such that barriers to the rapid and efficient "hand-off" between organizations are minimized. The success of this process is ensured by formulating a structured set of criteria for evaluating the roles and clinical relevance of each biomarker, along with criteria and strategies for determining the use of biomarkers in relationship to one another.

There have been some changes in the way the pharmaceutical industry conduct their business model of $R \& D$ process in. For example, in a recent report, Gautam et al. [100] analyzed data on key aspects (i.e. revenue distribution, research units, portfolio mix, and emerging markets) to identify key trends to gain insight into the change in strategic focus, realignment of $R \& D$ focus and focus toward targeted therapeutics and the growth of emerging markets. Their analysis revealed that there are several trends at play such as massive to lean; consolidation of R\&D footprint and shift from hubs to hotspots; primary to specialty care model. The big pharma has been shifting away from developing primary care and small-molecule medicines; and progressively tailoring their pipelines to specialty medicines and biologics targeted for high unmet medical needs; and; globally a West to East shift (i.e. the emerging markets of Asia, Latin America, Russia, Middle- East and Africa 
continue to lead revenue growth and innovation capabilities [101]).

In addition, mission-oriented translational research has been proposed. In this model health economics is integrated into all phases of translational research as an intrinsic component of any study aimed at improving outcomes for patients and intervention costs [122].

\section{Adopt open innovation and intellectual property (IP) models}

Due to the inherent significant difference between experts in their individual intuitive go/no-go decisions during the complex drug discovery and development process, new forms of multisource open innovation models such as crowdsourcing and crowd casting could help for rational decision-making [112]. Accordingly, an open innovation model with the increased openness, entrepreneurial awareness, entrepreneurial engagements, and engagements of wide-ranging skills and expertise may help them to improve the $R \& D$ process.

In classical business model, there are many stakeholders that collaboratively develop and package products whether they are drugs, drug targets, or biomarkers or even knowhow that require IP protection before publicly sharing any findings in the form of publications, etc. (and many of those findings in industry even are not published). However, this business model also slows down the progress and also results in wasted resources on similar scientific efforts due to a lack of transparency. This significantly affects inherent project uncertainty and decision-making modeling as well as entrepreneurial orientation. Because of this, an open innovation model (i.e. open IP platforms) differs from the classical closed innovation model when openness enables accelerated product development and at the same time avoids dead ends. However; this open innovation model somewhat needs to develop a strategy for cost and revenue sharing such that it becomes a win-win model that is structured in open networks and business consortia.

On the other hand, open innovation creates opportunities especially in lean times by breaking down conventional corporate boundaries, allowing ideas, people, and IP to flow freely both into and out of an organization [123, 124].

It has been suggested that [124], open innovation might in fact strengthen patent protection, induces the free sharing and dissemination of information; conversely, the exercise of traditional IP rights by innovative firms to protect their intellectual asset leads to a decrease in the strength of the patent system. Because of this, open innovation globalization has increased the need for cross-border, inter-firm open R\&D cooperation, and this has led to transparency and cross-fertilization of ideas and concepts in the $R \& D$ process across a variety of fields [125].
Open innovation model adopts a more effective R\&D strategy that requires information sharing and open IP platforms. As illustrated in Fig. 4 open innovation model emphasizes integrative science through collaboration, via establishing joint ventures or strategic alliances, opensharing of internal and external $R \& D$ functions and resources including IP sharing, as well as using existing knowledge (data), and taking up other multifaceted approaches and resulting benefits from advances on different fronts of new R\&D process.

Open innovation offers several benefits including the creation of high-value knowledge and resources. Since the open innovation model shares the burden of $R \& D$ cost and reduces $R \& D$ risk, it has the potential to create synergism between internal and external R\&D leading to the development of new technology and products for new markets, or displacing existing products in the current markets, or capturing the markets from other companies. Furthermore, new knowledge, technology, and products can potentially be out-licensed.

At the same time, open innovation also creates a number of risks and challenges, including revealing information not intended for sharing, the potential for the organizations to lose their competitive advantage as a result of shared intellectual property [124], the complexity of ownership of IP and sharing financial and intellectual returns from innovative products, knowledge, and technology.

Moreover, due to the highly dynamic nature of the R\&D landscape, and because different contexts may offer different challenges or opportunities for value creation or appropriation, the open innovation agreements must be updated regularly.

Despite the challenges, open innovation models based on global open innovation and development communities are emerging in various fields of science and business such as biomedicine, life sciences, engineering, and information technology. Therefore, it is imperative that when dealing with complex decision-making processes in biomedical research, implementing such open innovation and management models might be able to optimize decision-making and value creation for industry, society, and patients.

As a result, more collaborative and open innovation models are showing more acceptance in the pharmaceutical and biotech sectors. This is partly due to several factors such as need for collaboration for tackling highly complex nature of biomedical research, better and easier communication across the globe via the Internet, availability of experts for complex decision-making, the funding mechanisms encouraging such collaborations (or team work), increasing venture capital and entrepreneurs, philanthropists to fund such research, as well as the increasing interest from other interest groups including public 


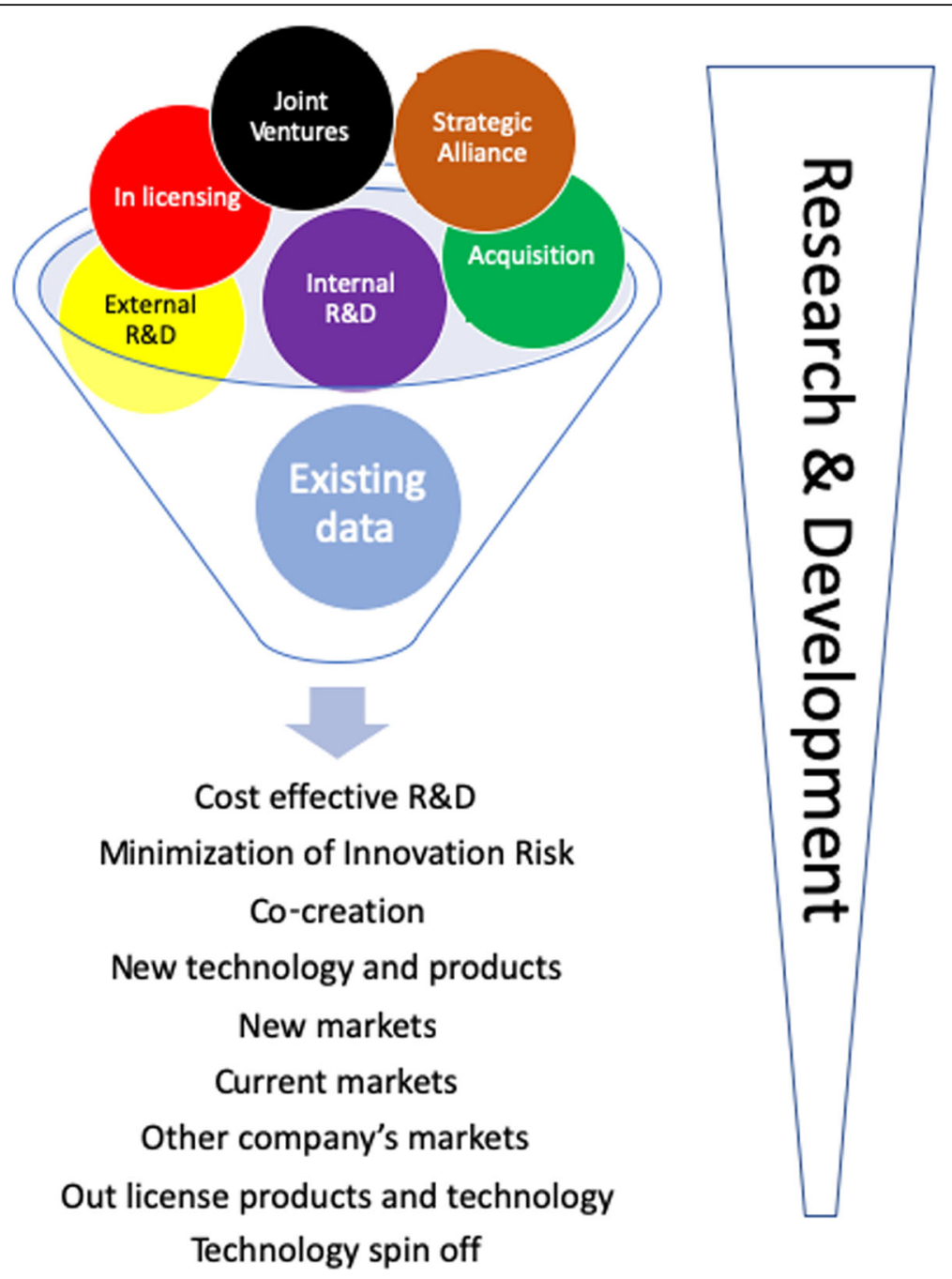

Fig. 4 Open Innovation Model emphasizes integrative science through collaboration, strategic alliance, open-sharing of internal R\&D and external $R \& D$, using existing knowledge (data), taking up other multifaceted approaches and accruing benefits from advances on different fronts of new drug discovery and development process to create internal and external knowledge and resources to create value and to capture a piece of that value. Because the open innovation model shares the innovation cost and minimizes innovation risk, it has the potential to self-sustain itself creating new technology and products for new markets or displacing existing products in the current markets as well as potential out licensing opportunities for the products and technology developed during this process

awareness and policymakers to support such collaborative biomedical research to accelerate better and faster drug and other relevant biomedical product development.

The last few years many pharmaceutical companies have begun using open innovation models $[126,127]$ to more dynamically adjust for innovation challenges with broader scientific feedbacks [100]. A case in point, the Drugs for Neglected Diseases initiative (DNDi) has established several partnerships with the private sector (i.e. GSK, Anacor) and with academia, https://www.dndi. org/newsletters/n16/dndi.php).

They have begun conduction joint biomedical research and ways of designing their IP-strategies to optimize the value extraction from these joint ventures. DNDi is an independent, not-for-profit drug or product development consortium established to discover and develop novel and improved treatments for neglected and mostly tropical diseases (i.e. malaria, leishmaniasis, sleeping sickness, and Chagas disease). DNDi was established in 2003 by publicly-funded research institutes from Brazil, India, Kenya, Malaysia along Institut Pasteur and NGOs like Médecins Sans Frontières (MSF) (https://www.dndi. org/newsletters/n16/edito.php). DNDi operates through a virtual model whereby all of its R\&D activities are outsourced, contributing to keeping development costs under control while providing high flexibility. As a consequence of this strategic option, the development of an efficient drug development program to address neglected 
diseases requires the establishment of strong agreements within the entire biomedical landscape. As a virtual R\&D organization, DNDi undertakes the complex and lengthy drug discovery and development processes by establishing effective partnerships with public and private organizations and to bring together their diverse complementary capabilities essential for developing new treatments. The partnership network consists of a diverse group of players including individual investigators, independent experts, academic groups, NGOs like MSF, major research centers, public institutions, biotech and pharmaceutical companies. The success of this business model is reflected in over 250 collaborations (research, technical, and funding agreements with both public and private partners) within the past 5 years. The success lies in bringing together individual, public and private partners who are motivated to make a significant difference for patients suffering from neglected diseases. As elaborated on the DNDi portal (https://www.dndi.org/newsletters/n16/edito.php), multiple key factors are at play for effective partnerships in this field including (1) innovative thinking to critical issues by engaging academia, public health institutes, biotech, or pharmaceutical industries, (2) common needs-driven objective, (3) the virtual model that enables delivery of timely scientific innovation, (4) strengthening existing local capabilities and project management to orchestrate and coordinate activities within the partnership networks, (5) partnerships with local and international donors and philanthropists which play a major role in funding the R\&D, (6) reciprocal benefits such as favorable public image, scientific information generated from a particular technology or compound (i.e. early stage development), access to R\&D grants through joint applications, and most importantly developing new and improved treatments. Based on the above principles, DNDi has established a partnership with industry (e.g. GSK, Anacor, now part of Pfizer) and academia. However, there is a need for more regulatory guidelines to safeguard access rights to scientific information and products developed from these partnerships which would help to accelerate the progress of the open innovation model.

In summary, although there could be many other factors that might be contributing to the failures in translation research, these are beyond the scope of this review. A more detailed discussion in each specific area affecting the translational research including the operational challenges [16] associated with bringing forward translational medicine within a coherent framework for translational research and potential solutions to overcome those challenges have been extensively discussed in the literature $[4,8,13,15-17,19,28,32,60,99,102$, $103,121,128-132]$. These include the need for new, efficient organizational models that promote innovation and team-oriented collaborative science, such as in an 'adhocracy' (i.e. a flexible, adaptable and informal form of organization that is defined by a lack of formal structure that employs specialized multidisciplinary teams grouped by functions) as proposed by Henry Mintzberg [46].

\section{Conclusion}

In closing, the success of the translation research from bench to bedside depends on the adoption of multidisciplinary team science and inter organizational collaborative model that synchronizes efforts and actions of all funding agencies, academia, nonprofit foundations, philanthropy, pharmaceutical and biotechnology industries, the public, and the policymakers, with the full support and backing of organizational leadership and funding agencies.

Despite the setbacks, there has been some progress of movement to cross the divide. For example, in recent years, many pharmaceutical companies have begun using open innovation models to address R\&D challenges. The challenge is to establish the equilibrium between innovation and healthy competition in the market in the context of drug discovery and development, marketing, and cost and revenue sharing. It is also noteworthy to mention that there are new breed of pharmaceutical companies emerging from emerging economies including China, India, Korea, and Brazil potentially with their unique $R \& D$ and business models to challenge the longheld leadership of US and European pharmaceutical companies. Last but not least, the future will also be affected by using AI in biomedical R\&D.

Furthermore, as eloquently summarized in a recent article [28], the scientific community, academic and research institutes, industry representatives, policy makers, and public in general must be open to the idea of integrating more inter-institutional, multidisciplinary collaborations, continue to invest in the next generation of researchers who may not fit into the traditional academic profile, and support the long path these researchers will have in front of them, and continue to build partnerships between academia and industry to utilize the strengths and expertise of all parties.

\footnotetext{
Abbreviations

3D: Three-Dimensional; Al: Artificial Intelligence; CAN: Cures acceleration network; CLIA: Clinical Laboratory Improvement Amendments; CMS: Centers for Medicare \& Medicaid Services; CTiD: Clinical trials in a dish; CTSAS: Clinical and Translational Science Awards; DOD: Department of Defense; E.g.: Exempl gratia; EDRN: Early Detection Research Network; EHR: Electronic Health Records; eMERGE: electronic Medical Records and Genomics Network; Etc.: Etcetera; FDA: The Food and Drug Administration; GWAS: Genome-wide Association Studies; HCV: Hepatitis C virus; HIV: human immunodeficiency virus; I.e.: Id est.; IND: Investigational New Drug; IP: Intellectual property; NCE: New Chemical Entities; NCGC: National Chemical Genomics Center; NCl: National Cancer Institute; NDA: New Drug Application; NIH: National Institutes of Health; NME: New Molecular Entity; PD: Pharmacodynamics; PK: Pharmacokinetics; R\&D: Research and Development; RAID: Rapid Access
} 
to Interventional Development; TRND: Therapeutics for Rare and Neglected Diseases; US: United States

\section{Acknowledgements}

I thank our affiliated institutes making this publication possible. We apologize to the many authors and colleagues whose works are not cited due to limited space.

\section{Review criteria}

Number of scientific articles with terms translational, preclinical, clinical, and biomedical research, drug development, reproducibility of biomedical research data, failure of drug development and clinical trials in the abstract were queried. The search was restricted to the most recent studies in this field and all searches were limited to studies published in English.

\section{Authors' contributions}

AAS wrote the manuscript and agrees with the manuscript's results and conclusions. The author has read and confirms that he meets, ICMJE criteria for authorship.

\section{Authors' information}

\section{Attila A Seyhan, PhD.}

Director of Translational Oncology Operations, Joint Program in Cancer Biology, Brown University and Lifespan Cancer Institute; reports to Associate Dean for Oncologic Sciences, Warren Alpert Medical School, Brown University, Providence, Rl.

Adjunct Associate Professor, Department of Pathology and Laboratory Medicine, Warren Alpert Medical School, Brown University, Providence, RI. Correspondence: Attila Seyhan, PhD, Attila_seyhan@brown.edu; Attila_ seyhan@yahoo.com

\section{Funding}

No funding involved in the preparation of this article.

\section{Availability of data and materials}

Not applicable.

\section{Ethics approval and consent to participate}

This article does not contain any studies with human participants or animals performed by any of the authors. Informed consent was not required for the preparation of this review article as it used secondary sources only.

\section{Consent for publication}

The Author grants the Publisher the sole and exclusive license of the full copyright in the Contribution, which license the Publisher hereby accepts.

\section{Competing interests}

The author declares that he has no competing interests.

Received: 5 July 2019 Accepted: 6 November 2019

\section{Published online: 18 November 2019}

\section{References}

1. Cohrs RJ, Martin T, Ghahramani P, Bidaut L, Higgins PJ, Shahzad A. Translational medicine definition by the European Society for Translational Medicine. Eur J Mol Clin Med. 2014;2:86

2. Lum C, Koper CS. Evidence-based policing: translating research into practice. USA: Oxford University Press; 2017.

3. Carini C, Seyhan AA, Fidock MD, van Gool AJ. Definitions and conceptual framework of Biomarkers in Precision Medicine. Handbook of Biomarkers and Precision Medicine. In: Claudio Carini MF, van Gool A, editors. Handbook of Biomarkers and Precision Medicine. New York: Chapman and Hall/CRC; 2019. p. 2.

4. Woolf $\mathrm{SH}$. The meaning of translational research and why it matters. JAMA 2008;299:211-3.

5. Fontanarosa PB, DeAngelis CD. Basic science and translational research in JAMA. JAMA. 2002;287:1728.

6. Ashburn TT, Thor KB. Drug repositioning: identifying and developing new uses for existing drugs. Nat Rev Drug Discov. 2004;3:673-83.

7. Scannell JW, Blanckley A, Boldon H, Warrington B. Diagnosing the decline in pharmaceutical R\&D efficiency. Nat Rev Drug Discov. 2012;11:191-200.
8. Ioannidis JP. Why Most clinical research is not useful. PLoS Med. 2016;13: e1002049.

9. Ioannidis JPA. Why most published research findings are false. PLoS Med. 2005:2:696-701.

10. Medicine lo. Drug repurposing and repositioning: workshop summary. Washington, DC: The National Academies Press; 2014.

11. Pammolli F, Magazzini L, Riccaboni M. The productivity crisis in pharmaceutical R\&D. Nat Rev Drug Discov. 2011;10:428-38.

12. Waring MJ, Arrowsmith J, Leach AR, Leeson PD, Mandrell S, Owen RM, Pairaudeau G, Pennie WD, Pickett SD, Wang J, et al. An analysis of the attrition of drug candidates from four major pharmaceutical companies. Nat Rev Drug Discov. 2015;14:475-86.

13. Zeggini E, Gloyn AL, Barton AC, Wain LV. Translational genomics and precision medicine: moving from the lab to the clinic. Science. 2019;365: 1409-13.

14. Schork NJ. Personalized medicine: time for one-person trials. Nature. 2015; 520:609-11.

15. In The CTSA Program at NIH. In: Leshner Al, Terry SF, Schultz AM, Liverman CT, editors. Opportunities for Advancing Clinical and Translational Research. Edited by. Washington (DC): The National Academies Collection: Reports funded by National Institutes of Health; 2013.

16. Blumberg RS, Dittel B, Hafler D, von Herrath M, Nestle FO. Unraveling the autoimmune translational research process layer by layer. Nat Med. 2012;18: $35-41$.

17. FitzGerald GA. Moving clinical research in academic medical centres up the value chain. Nat Rev Drug Discov. 2009;8:597.

18. Sabroe I, Dockrell DH, Vogel SN, Renshaw SA, Whyte MKB, Dower SK. Identifying and hurdling obstacles to translational research. Nat Rev Immunol. 2007;7:77-82.

19. Seyhan AA. In: Claudio Carini MF, van Gool A, editors. Lost in Translation the challenges with the use of animal models in translational research. New York: Chapman and Hall/CRC; 2019. p. 36.

20. Garner JP, Gaskill BN, Weber EM, Ahloy-Dallaire J, Pritchett-Corning KR. Introducing Therioepistemology: the study of how knowledge is gained from animal research. Lab Anim. 2017;46:103-13.

21. Butler D. Translational research: crossing the valley of death. Nature. 2008; 453:840-2.

22. Roberts SF, Fischhoff MA, Sakowski SA, Feldman EL. Perspective: transforming science into medicine: how clinician-scientists can build bridges across research's "valley of death". Acad Med. 2012;87:266-70.

23. Paul SM, Mytelka DS, Dunwiddie CT, Persinger CC, Munos BH, Lindborg SR, Schacht AL. How to improve R\&D productivity: the pharmaceutical industry's grand challenge. Nat Rev Drug Discov. 2010;9(3):203-14.

24. Kola I, Landis J. Can the pharmaceutical industry reduce attrition rates? Nat Rev Drug Discov. 2004;3:711-5.

25. Hay M, Thomas DW, Craighead JL, Economides C, Rosenthal J. Clinical development success rates for investigational drugs. Nat Biotechnol. 2014; 32:40-51.

26. DiMasi JA, Hansen RW, Grabowski HG. The price of innovation: new estimates of drug development costs. J Health Econ. 2003;22:151-85.

27. Morgan S, Grootendorst P, Lexchin J, Cunningham C, Greyson D. The cost of drug development: a systematic review. Health Policy. 2011;100:4-17.

28. Fernandez-Moure JS. Lost in translation: The gap in scientific advancements and clinical application. Front Bioeng Biotechnol. 2016;4:43.

29. DiMasi JA, Feldman L, Seckler A, Wilson A. Trends in risks associated with new drug development: success rates for investigational drugs. Clin Pharmacol Ther. 2010;87:272-7.

30. Arrowsmith J, Miller P. Trial watch: phase II and phase III attrition rates 2011 2012. Nat Rev Drug Discov. 2013;12:569.

31. Akhtar A. The flaws and human harms of animal experimentation. Camb Q Healthc Ethics. 2015;24:407-19.

32. Seyhan AA, Carini C. Are innovation and new technologies in precision medicine paving a new era in patients centric care? J Transl Med. 2019;17:114.

33. Mullin R, Chemical, News E. Cost to Develop New Pharmaceutical Drug Now Exceeds \$2.5B. In: Scientific American [Internet]. Available: https:// www.scientificamerican.com/article/cost-to-develop-new-pharmaceuticaldrug-now-exceeds-2-5b/.

34. DiMasi JA, Grabowski HG, Hansen RW. Innovation in the pharmaceutical industry: new estimates of R\&D costs. J Health Econ. 2016;47:20-33.

35. Densen P. Challenges and opportunities facing medical education. Trans Am Clin Climatol Assoc. 2011;122:48-58. 
36. Nosengo N. Can you teach old drugs new tricks? Nature. 2016;534:314-6.

37. Bajorath J: Faculty of 1000 evaluation for Clinical development success rates for investigational drugs. F1000 - Post-publication peer review of the biomedical literature 2015.

38. Bunnage ME. Getting pharmaceutical R\&D back on target. Nat Chem Biol. 2011;7:335-9.

39. Lin A, Giuliano CJ, Palladino A, John KM, Abramowicz C, Yuan ML, Sausville EL, Lukow DA, Liu L, Chait AR, et al. Off-target toxicity is a common mechanism of action of cancer drugs undergoing clinical trials. Sci Transl Med. 2019;11:eaaw8412.

40. Seyhan AA. Biomarkers in drug discovery and development. Eur Biopharm Rev. 2010(5):19-25.

41. Seyhan AA. microRNAs with different functions and roles in disease development and as potential biomarkers of diabetes: progress and challenges. Mol BioSyst. 2015;11:1217-34.

42. Seyhan A, Carini C. In: Carini C, Menon S, Chang M, editors. Biomarkers for drug development: The time is now! Clinical and Statistical Considerations in Personalized MedicinePublisher. New York: Chapman \& Hall - CRC Press Editors; 2014. p. 16-41.

43. Carini C, Seyhan A. In: Barker KB, Menon SM, D'Agostino RB, Sr SX, Jin B, editors. From Isolation to Integration: A Systems Biology Approach for the Discovery of Therapeutic Targets and Biomarkers. Biosimilar Clinical Development: Scientific Considerations and New Methodologies: Edited By; 2016. p. 2.

44. El-Deiry WS, Goldberg RM, Lenz HJ, Shields AF, Gibney GT, Tan AR, Brown J, Eisenberg B, Heath El, Phuphanich S, et al. The current state of molecular testing in the treatment of patients with solid tumors, 2019. CA Cancer J Clin. 2019;69:305-43.

45. Aronson JK, Ferner RE. Biomarkers-A General Review. Curr Protoc Pharmacol. 2017;76:9.23.1-9.23.17.

46. Mintzberg H. Organizational design: fit or fashion. Bus Rev. 1981;59:103-16.

47. Tuaeva NO, Falzone L, Porozov YB, Nosyrev AE, Trukhan VM, Kovatsi L, Spandidos DA, Drakoulis N, Kalogeraki A, Mamoulakis C, Tzanakakis G, Libra M, Tsatsakis A. Translational application of circulating DNA in oncology: Review of the Last Decades Achievements. Cells. 2019;8: 1251.

48. Smith CM, Catchpoole D, Hutvagner G. Non-coding RNAs in pediatric solid tumors. Front Genet. 2019;10:798.

49. Machackova T, Prochazka V, Kala Z, Slaby O. Translational Potential of MicroRNAs for Preoperative Staging and Prediction of Chemoradiotherapy Response in Rectal Cancer. Cancers. 2019;11:1545.

50. Garufi G, Seyhan AA, Pasarica M. Elevated secreted frizzled-related protein 4 in obesity: a potential role in adipose tissue dysfunction. Obesity (Silver Spring). 2015;23:24-7.

51. Nunez Lopez YO, Garufi G, Seyhan AA. Altered levels of circulating cytokines and microRNAs in lean and obese individuals with prediabetes and type 2 diabetes. Mol BioSyst. 2016;13:106-21.

52. Seyhan AA, Nunez Lopez YO, Xie H, Yi F, Mathews C, Pasarica M, Pratley RE. Pancreas-enriched miRNAs are altered in the circulation of subjects with diabetes: a pilot cross-sectional study. Sci Rep. 2016:6:31479.

53. Nunez Lopez YO, Coen PM, Goodpaster BH, Seyhan AA. Gastric bypass surgery with exercise alters plasma microRNAs that predict improvements in cardiometabolic risk. Int J Obes. 2017:41:1121-30.

54. Nunez Lopez YO, Pittas AG, Pratley RE, Seyhan AA. Circulating levels of miR7, miR-152 and miR-192 respond to vitamin D supplementation in adults with prediabetes and correlate with improvements in glycemic control. J Nutr Biochem. 2017:49:117-22.

55. Pachori AS, Madan M, Nunez Lopez YO, Yi F, Meyer C, Seyhan AA Reduced skeletal muscle secreted frizzled-related protein 3 is associated with inflammation and insulin resistance. Obesity (Silver Spring). 2017; 25:697-703.

56. Nunez Lopez YO, Garufi G, Pasarica M, Seyhan AA. Elevated and correlated expressions of miR-24, miR-30d, miR-146a, and SFRP-4 in human abdominal adipose tissue play a role in adiposity and insulin resistance. Int J Endocrinol. 2018:2018:7351902

57. Nunez Lopez YO, Retnakaran R, Zinman B, Pratley RE, Seyhan AA. Predicting and understanding the response to short-term intensive insulin therapy in people with early type 2 diabetes. Mol Metab. 2019;20:63-78.

58. Selleck MJ, Senthil M, Wall NR. Making Meaningful Clinical Use of Biomarkers. Biomark Insights. 2017;12:1177271917715236.

59. Njoku K, Chiasserini D, Whetton AD, Crosbie EJ. Proteomic Biomarkers for the Detection of Endometrial Cancer. Cancers. 2019;11(10):1572.
60. Yurkovich, J.T., Tian, Q., Price, N.D. et al. A systems approach to clinical oncology uses deep phenotyping to deliver personalized care. Nat Rev Clin Oncol. 2019. https://doi.org/10.1038/s41571-019-0273-6.

61. Yehia L, Eng C. Largescale population genomics versus deep phenotyping: brute force or elegant pragmatism towards precision medicine. NPJ Genom Med. 2019:4:6.

62. Weng C, Shah N, Hripcsak G. Call for papers: deep phenotyping for precision medicine. J Biomed Inform. 2018:87:66-7.

63. Robinson PN. Deep phenotyping for precision medicine. Hum Mutat. 2012; 33:777-80.

64. Ma P, Zemmel R. From the analyst's couch: value of novelty? Nat Rev Drug Discov. 2002;1:571-2.

65. Shuler ML. Organ-, body- and disease-on-a-chip systems. Lab Chip. 2017;17: 2345-6.

66. Colquhoun D. An investigation of the false discovery rate and the misinterpretation of p-values. R Soc Open Sci. 2014;1:140216.

67. Chung K. Rapid drug screen using 3D tumor organoids. Sci Transl Med. 2018;10:eaar7507.

68. Sachs N, de Ligt J, Kopper O, Gogola E, Bounova G, Weeber F, Balgobind AV, Wind K, Gracanin A, Begthel H, et al. A Living Biobank of Breast Cancer Organoids Captures Disease Heterogeneity. Cell. 2018;172: 373-386.e310

69. Kwok TCY, Ricker N, Fraser R, Chan AW, Burns A, Stanley EF, McCourt P, Cutler SR, Roy PJ. A small-molecule screen in C. elegans yields a new calcium channel antagonist. Nature. 2006:441:91-5.

70. Zon LI, Peterson RT. In vivo drug discovery in the zebrafish. Nat Rev Drug Discov. 2005:4:35-44.

71. Renshaw SA, Loynes CA, Trushell DMl, Elworthy S, Ingham PW, Whyte MKB. A transgenic zebrafish model of neutrophilic inflammation. Blood. 2006;108:3976-8

72. Fermini B, Coyne ST, Coyne KP. Clinical trials in a dish: a perspective on the coming revolution in drug development. SLAS Discov. 2018. https://doi.org/ $10.1177 / 2472555218775028$.

73. Glicksberg BS, Johnson KW, Dudley JT. The next generation of precision medicine: observational studies, electronic health records, biobanks and continuous monitoring. Hum Mol Genet. 2018;27:R56-62

74. Yao L, Zhang Y, Li Y, Sanseau P, Agarwal P. Electronic health records: implications for drug discovery. Drug Discov Today. 2011;16:594-9.

75. Shameer K, Glicksberg BS, Hodos R, Johnson KW, Badgeley MA, Readhead B, Tomlinson MS, O'Connor T, Miotto R, Kidd BA, et al. Systematic analyses of drugs and disease indications in RepurposeDB reveal pharmacological, biological and epidemiological factors influencing drug repositioning. Brief Bioinform. 2018;19:656-78.

76. Shameer K, Johnson KW, Glicksberg BS, Dudley JT, Sengupta PP. Machine learning in cardiovascular medicine: are we there yet? Heart. 2018;104:1156-64.

77. Johnson KW, Shameer K, Glicksberg BS, Readhead B, Sengupta PP, Bjorkegren JLM, Kovacic JC, Dudley JT. Enabling precision cardiology through multiscale biology and systems medicine. JACC Basic Transl Sci. 2017;2:311-27.

78. Dewey FE, Gusarova V, Dunbar RL, O'Dushlaine C, Schurmann C, Gottesman O, McCarthy S, Van Hout CV, Bruse S, Dansky HM, et al. Genetic and pharmacologic inactivation of ANGPTL3 and cardiovascular disease. N Engl J Med. 2017:377:211-21.

79. Graham MJ, Lee RG, Brandt TA, Tai LJ, Fu W, Peralta R, Yu R, Hurh E, Paz E, McEvoy BW, et al. Cardiovascular and metabolic effects of ANGPTL3 antisense oligonucleotides. N Engl J Med. 2017;377:222-32.

80. Wilke RA, Xu H, Denny JC, Roden DM, Krauss RM, McCarty CA, Davis RL, Skaar T, Lamba J, Savova G. The emerging role of electronic medical Records in Pharmacogenomics. Clin Pharmacol Ther. 2011:89:379-86.

81. Bush WS, Crosslin DR, Owusu-Obeng A, Wallace J, Almoguera B, Basford MA Bielinski SJ, Carrell DS, Connolly JJ, Crawford D, et al. Genetic variation among 82 Pharmacogenes: The PGRNseq data from the eMERGE network. Clin Pharmacol Ther. 2016;100:160-9.

82. Khan R, Mittelman D. Consumer genomics will change your life, whether you get tested or not. Genome Biol. 2018;19:120.

83. Wynn J, Chung WK. 23andMe paves the way for direct-to-consumer genetic health risk tests of limited clinical utility. Ann Intern Med. 2017;167:125-6.

84. Tandy-Connor S, Guiltinan J, Krempely K, LaDuca H, Reineke P, Gutierrez S, Gray $P$, Tippin Davis B. False-positive results released by direct-to-consumer genetic tests highlight the importance of clinical confirmation testing for appropriate patient care. Genet Med. 2018;20:1515-21. 
85. Stoekle HC, Mamzer-Bruneel MF, Vogt G, Herve C. 23andMe: a new twosided data-banking market model. BMC Med Ethics. 2016;17:19.

86. Strittmatter SM. Overcoming drug development bottlenecks with repurposing: old drugs learn new tricks. Nat Med. 2014;20:590-1.

87. Yang YS, Marder SR, Green MF. Repurposing drugs for cognition in schizophrenia. Clin Pharmacol Ther. 2016:101:191-3.

88. Sleigh SH, Barton CL. Repurposing strategies for therapeutics. Pharmaceut Med. 2010;24:151-9.

89. Pollak M. Overcoming drug development bottlenecks with repurposing: repurposing biguanides to target energy metabolism for cancer treatment. Nat Med. 2014;20:591-3.

90. Zhang L, Kebebew E. Repurposing existing drugs for the treatment of thyroid cancer. Expert Rev Endocrinol Metab. 2012;7:369-71.

91. Ranjan A, Srivastava SK. Abstract 1251: repurposing antipsychotic drug Penfluridol for cancer treatment. Cancer Res. 2014:74:1251.

92. Fagan SC. Drug repurposing for drug development in stroke. Pharmacotherapy. 2010;30:51S-4S.

93. Mercado G, Hetz C. Drug repurposing to target proteostasis and prevent neurodegeneration: accelerating translational efforts. Brain. 2017:140:1544-7.

94. Telleria CM. Drug Repurposing for Cancer Therapy. J Cancer Sci Ther. 2012; 04:ix

95. Sharlow ER. Revisiting repurposing. Assay Drug Dev Technol. 2016;14:554-6.

96. Zheng W, Sun W, Simeonov A. Drug repurposing screens and synergistic drug-combinations for infectious diseases. Br J Pharmacol. 2018;175(2):18191.

97. Mucke HAM, Mucke E. Sources and targets for drug repurposing: landscaping transitions in therapeutic space. Drug Repurposing Rescue Repositioning. 2015;1:22-7.

98. Pushpakom S, Iorio F, Eyers PA, Escott K, Hopper S, Wells A, Doig A, Guilliams T, Latimer J, McNamee C, et al. Drug repurposing: progress, challenges and recommendations. Nat Rev Drug Discov. 2019;18:41-58.

99. Ioannidis JPA. How to Make More Published Research True. PLoS Med. 2014 11:e1001747.

100. Gautam A, Pan X. The changing model of big pharma: impact of key trends. Drug Discov Today. 2016;21:379-84

101. Gautam A, Yang S. Market watch: a framework for biomedical innovation in emerging markets. Nat Rev Drug Discov. 2014;13:646-7.

102. Mankoff SP, Brander C, Ferrone S, Marincola FM. Lost in translation: obstacles to translational medicine. J Transl Med. 2004;2:14.

103. Disis ML, Slattery JT. The road we must take: multidisciplinary team science. Sci Transl Med. 2010;2:22cm29.

104. Post C, De Lia E, DiTomaso N, Tirpak TM, Borwankar R. Capitalizing on thought diversity for innovation. Res Technol Manag. 2009;52:14-25.

105. McCarthy A, Garavan TN. Team learning and metacognition: a neglected area of HRD research and practice. Adv Dev Hum Resour. 2008;10:509-24.

106. Sugarman J, Califf RM. Ethics and regulatory complexities for pragmatic clinical trials. JAMA. 2014;311:2381-2.

107. Goldstein CE, Weijer C, Brehaut JC, Fergusson DA, Grimshaw JM, Horn AR, Taljaard M. Ethical issues in pragmatic randomized controlled trials: a review of the recent literature identifies gaps in ethical argumentation. BMC Med Ethics. 2018;19:14.

108. Meltzer DO, Hoomans T, Chung JW, Basu A. Minimal modeling approaches to value of information analysis for Health Research. Med Decis Mak. 2011; 31:E1-E22.

109. Detsky AS. Are clinical trials a cost-effective investment? JAMA. 1989;262: 1795-800.

110. Pham CT, Karnon JD, Middleton PF, Bloomfield FH, Groom KM, Crowther CA, Mol BW. Randomised clinical trials in perinatal health care: a costeffective investment. Med J Aust. 2017;207:289-93.

111. Bode-Greuel KM, Nickisch KJ. Value-driven project and portfolio management in the pharmaceutical industry: drug discovery versus drug development - commonalities and differences in portfolio management practice. J Commer Biotechnol. 2008;14:307-25.

112. Cowlrick I, Hedner T, Wolf R, Olausson M, Klofsten M. Decision-making in the pharmaceutical industry: analysis of entrepreneurial risk and attitude using uncertain information. RD Manag. 2011;41:321-36.

113. Pritchard JF, Jurima-Romet M, Reimer ML, Mortimer E, Rolfe B, Cayen MN. Making better drugs: decision gates in non-clinical drug development. Nat Rev Drug Discov. 2003;2:542-53.

114. Hammond KR. Probabilistic functioning and the clinical method. Psycho Rev. 1955;62:255-62.
115. Hedner T. Change in the pharmaceutical industry : aspects on innovation, Entrepreneurship, Openness, and Decision Making. Doctoral thesis, comprehensive summary. New York: Linköping University Electronic Press, Linköping Studies in Science and Technology Dissertations; 2012.

116. Betz UA. Portfolio management in early stage drug discovery - a traveler's guide through uncharted territory. Drug Discov Today. 2011;16:609-18.

117. Ringel M, Tollman P, Hersch G, Schulze U. Does size matter in R\&D productivity? If not, what does? Nat Rev Drug Discov. 2013;12:901-2.

118. Coudray N, Ocampo PS, Sakellaropoulos T, Narula N, Snuderl M, Fenyo D, Moreira AL, Razavian N, Tsirigos A. Classification and mutation prediction from non-small cell lung cancer histopathology images using deep learning. Nat Med. 2018;24:1559.

119. Ocampo P, Moreira A, Coudray N, Sakellaropoulos T, Narula N, Snuderl M, Fenyo D, Razavian N, Tsirigos A. Classification and mutation prediction from non-small cell lung Cancer histopathology images using deep learning. J Thorac Oncol. 2018;13:S562.

120. Leiserson MDM, Syrgkanis V, Gilson A, Dudik M, Gillett S, Chayes J, Borgs C, Bajorin DF, Rosenberg JE, Funt $S$, et al. A multifactorial model of T cell expansion and durable clinical benefit in response to a PD-L1 inhibitor. PLoS One. 2018:13:e0208422.

121. Wagner PD, Srivastava S. New paradigms in translational science research in cancer biomarkers. Transl Res. 2012;159:343-53.

122. Jonsson B, Sullivan R. Mission-oriented translational cancer research - health economics. Mol Oncol. 2019:13:636-47.

123. Chesbrough HW, Garman AR. How open innovation can help you cope in lean times. Harv Bus Rev. 2009:87:68-76 128.

124. Da Silva MAPM. Open innovation and IPRs: mutually incompatible or complementary institutions? J Innov Knowl. 2019:4:248-52.

125. Martinez-Noya A, Narula R. What more can we learn from R\&D alliances? A review and research agenda. Brq-Bus Res Q. 2018;21:195-212.

126. Rebhan M. Towards a systems approach for chronic diseases, based on health state modeling. F1000Res. 2017;6:309.

127. Yu HW. Bridging the translational gap: collaborative drug development and dispelling the stigma of commercialization. Drug Discov Today. 2016;21: 299-305.

128. Moore HM, Kelly A, Jewell SD, McShane LM, Clark DP, Greenspan R, Hainaut $P$, Hayes DF, Kim P, Mansfield E, et al. Biospecimen reporting for improved study quality. Biopreserv Biobank. 2011;9:57-70.

129. Finkbeiner S. Bridging the valley of death of therapeutics for neurodegeneration. Nat Med. 2010;16:1227-32.

130. Sung NS, Crowley WF Jr, Genel M, Salber P, Sandy L, Sherwood LM, Johnson SB, Catanese V, Tilson H, Getz K, et al. Central challenges facing the national clinical research enterprise. JAMA. 2003;289:1278-87.

131. Horig H, Marincola E, Marincola FM. Obstacles and opportunities in translational research. Nat Med. 2005;11:705-8

132. Littman BH, Di Mario L, Plebani M, Marincola FM. What's next in translational medicine? Clin Sci (Lond). 2007;112:217-27.

\section{Publisher's Note}

Springer Nature remains neutral with regard to jurisdictional claims in published maps and institutional affiliations.

Ready to submit your research? Choose BMC and benefit from:

- fast, convenient online submission

- thorough peer review by experienced researchers in your field

- rapid publication on acceptance

- support for research data, including large and complex data types

- gold Open Access which fosters wider collaboration and increased citations

- maximum visibility for your research: over $100 \mathrm{M}$ website views per year

At BMC, research is always in progress.

Learn more biomedcentral.com/submissions 